\title{
Neonatal estrogenic exposure suppresses PTEN-related endometrial carcinogenesis in recombinant mice
}

\author{
Monjura Begum ${ }^{1}$, Hironori Tashiro ${ }^{2}$, Hidetaka Katabuchi ${ }^{2}$, Akira Suzuki $^{3}$, Robert J Kurman ${ }^{4}$ \\ and Hitoshi Okamura ${ }^{1}$ \\ ${ }^{1}$ Department of Reproductive Medicine and Surgery, Faculty of Medical and Pharmaceutical Sciences, \\ Kumamoto University, Honjo, Kumamoto City, Kumamoto, Japan; ${ }^{2}$ Department of Gynecology, Faculty of \\ Medical and Pharmaceutical Sciences, Kumamoto University, Honjo, Kumamoto City, Kumamoto, Japan; \\ ${ }^{3}$ Department of Molecular Biology, Akita University School of Medicine, Hondo, Akita City, Akita, Japan and \\ ${ }^{4}$ Division of Gynecologic Pathology, Department of Pathology, The Johns Hopkins University School of \\ Medicine, Baltimore, MD, USA
}

\begin{abstract}
Human endometrial carcinomas, as well as complex atypical hyperplasias (CAH), are estrogen related and frequently have mutations in the PTEN gene. However, the mutual contribution of estrogen and PTEN mutations to endometrial carcinogenesis in vivo is unknown. To address this issue, we investigated whether neonatal estrogenic treatments augment the incidence of CAH and carcinomas in murine PTEN (mPTEN) heterozygous $(+I-)$ mutant mice, an animal model for endometrial carcinoma. Low doses of diethylstilbestrol (1 $\mathrm{ng} / \mathrm{g} / \mathrm{day})$, genistein $\left(50 \mu \mathrm{g} / \mathrm{g} /\right.$ day) in phytoestrogens, estriol $\left(E_{3}\right)(4 \mu \mathrm{g} / \mathrm{g} /$ day), and vehicle (ethanol and corn oil) were administered subcutaneously daily to neonatal pups from the 1st to 5th day after birth. At 52 weeks of age, the morphological changes in the endometrium, and uterine expression of Hoxa 10 and Hoxa 11, were evaluated. These Hoxa genes are abdominal B-type homeobox genes, which normally regulate differentiation of the Müllerian duct. The incidence of $\mathrm{CAH}$ and adenocarcinomas of the endometrium was significantly decreased by the neonatal estrogenic treatments in the $\mathrm{mPTEN}+I-$ mice. Coincidentally, all treatments significantly decreased the stromal cell density, and $\mathrm{CAH}$ and adenocarcinomas rarely developed in the epithelium adjacent to the affected endometrial stroma. Moreover, the uterine expression of Hoxa $10 \mathrm{in}$ mice with neonatal genistein and $E_{3}$ treatments, and that of Hoxa 11 in mice with all treatments, was significantly lower when compared with vehicle alone. Taken together, neonatal estrogenic exposure induced stromal atrophy and/or hyalinization accompanied by repressed expression of Hoxa 10 and Hoxa 11, and exerted an inhibitory effect on PTEN-related tumorigenesis. These findings provide new insight into the interaction between endometrial epithelium and stroma in endometrial carcinogenesis in vivo.
\end{abstract}

Laboratory Investigation (2006) 86, 286-296. doi:10.1038/labinvest.3700380; published online 9 January 2006

Keywords: PTEN mutation; endometrial carcinoma; estrogen; neonate; mouse

Endometrial carcinoma is the most common malignancy of the female genital tract and fifth leading cancer in women worldwide. ${ }^{1}$ There are two main pathogenetic types of endometrial carcinoma. Endometrioid adenocarcinoma or type I, the most common type, is frequently related to unopposed estrogen stimulation, that is, polycystic ovarian

Correspondence: Dr H Tashiro, MD, PhD, Department of Gynecology, Faculty of Medical and Pharmaceutical Sciences, Kumamoto University, 1-1-1 Honjo, Kumamoto City, Kumamoto 860-8556, Japan.

E-mail: htashiro@kaiju.medic.kumamoto-u.ac.jp

Received 15 September 2005; revised 8 November 2005; accepted 9 November 2005; published online 9 January 2006 syndrome (PCOS), obesity, or exogenous estrogen single use. ${ }^{2,3}$ Serous carcinoma or type II is not related to estrogen stimulation and has a more aggressive clinical course, with a high incidence of metastasis. $^{2,3}$

Endometrioid adenocarcinoma usually shows microsatellite instability and mutation or methylation in the promoters of DNA mismatch repair genes $(M L H 1, M S H 2)^{4,5}$ and mutations in the K-ras, ${ }^{6,7} \beta$ catenin,${ }^{8}$ and PTEN genes. ${ }^{9-11}$ Mutations in p53 gene are identified as a late event in a small percentage of endometrioid carcinomas, and are often associated with high-grade endometrioid or serous adenocarcinoma. ${ }^{12-14}$ Among the genetic alterations in endometrioid adenocarcinomas, the PTEN gene is most 
frequently mutated. This gene is a common tumor suppressor gene that is located on chromosome $10 \mathrm{q} 23$, and is frequently associated with loss of heterozygosity in human carcinomas. ${ }^{15-17}$ This mutation has been found in $26-80 \%$ of endometrioid carcinomas and in $18-55 \%$ of precancerous lesions, that is, complex atypical hyperplasia (CAH). ${ }^{18-21}$ Recombinant mice with a targeted deletion of exons 3-5 of the murine (m) PTEN gene on chromosome 19 have been created to understand the biological activity of this tumor suppressor gene. ${ }^{22,23}$ Homozygous mutant mice lacking exons 3-5 of the mPTEN gene die in the embryonic stage. ${ }^{22}$ The mutation of one allele is sufficient to produce neoplasia in some organs, including the prostate, endometrium, lymph node, gastrointestinal tract, thyroid, breast, and thymus, which have phenotypic correlation with tumors arising in patients suffering from Cowden's syndrome. ${ }^{24,25}$ As a particularly high incidence of endometrial hyperplasia as well as adenocarcinomas has been detected, mPTEN+1mice are suitable as an animal model for investigating the role of the PTEN gene in endometrial carcinogenesis. ${ }^{26}$ In an attempt to expand this mouse model, Wang et $a l^{27}$ recently generated $\mathrm{mPTEN}+$ /and Mlh1 null (mismatch repair-deficient) doublemutant mice, which accelerated endometrial carcinogenesis.

Estrogens have been implicated as an important etiological factor in endometrial carcinogenesis. There is intense scientific and public interest in the concept that inadvertent and developmental exposure to synthetic estrogenic agents or even to natural substances that possess estrogenic activity may affect carcinogenesis in reproductive organs. Newbold et $a l^{28,29}$ reported a high incidence of endometrial adenocarcinomas at 78 weeks of age after neonatal exposure to diethylstilbestrol (DES; $1 \mathrm{ng} / \mathrm{g}$ of body weight/day) for the 1st to 5th day after birth in CD-1 mice. Besides DES, a low dose of genistein $(50 \mu \mathrm{g} / \mathrm{g} /$ day $)$ in phytoestrogens also frequently induced endometrial carcinomas. ${ }^{29}$ Many human infants are exposed to this compound as a component of soy-based infant formulas. An infant consuming soy-based infant formula would ingest $\sim 9 \mathrm{mg} / \mathrm{kg}(\mu \mathrm{g} / \mathrm{g})$ of genistein per day.

This aberrant stimulation by estrogenic agents during the developmental period may disrupt the proper expression of estrogen regulated genes, resulting in altered development of the endometrial stroma, that is, atrophic or hyalinized stroma. ${ }^{30-32}$ Recently, neonatal DES exposure was shown to repress the uterine expression of the abdominal B-type homeobox genes, Hoxa 10 and Hoxa 11, followed by significant loss in stromal development. ${ }^{33,34}$ Furthermore, mice lacking either Hoxa 10 or Hoxa 11 exhibited reproductive tract phenotypes resembling those of mice treated with developmental DES exposure. ${ }^{35-37}$ Hoxa 10 is expressed in endometrial epithelium and stroma, while Hoxa 11 expression is restricted to the stroma. ${ }^{38}$ The deve- lopment of both epithelium and stroma are thought to be under the regulation of Hoxa $11 .^{39}$

The present study was designed to investigate the neonatal estrogenic effect in PTEN-related carcinogenesis. Our preliminary study showed that $\mathrm{CAH}$ and endometrial carcinomas were observed in $93 \%$ (14 of 15 mice) and in $33 \%$ (5 of 15 mice), respectively, of $\mathrm{mPTEN}+1-$ mice at 52 weeks of age (unpublished data). Based on these findings, we examined whether low doses neonatal estrogenic treatments promote the incidence of $\mathrm{CAH}$ and endometrial carcinomas in $\mathrm{mPTEN}+/-$ mice and their wild-type littermates. Surprisingly, the incidence of $\mathrm{CAH}$ and adenocarcinomas of the endometrium was dramatically decreased by neonatal estrogenic treatments in $\mathrm{mPTEN}+/-$ mice. Simultaneously, neonatal estrogenic exposure induced stromal atrophy and/or hyalinization and repressed uterine expression of Hoxa 10 and Hoxa 11. These findings indicate that endometrial stromal cells play an important role in PTEN-related tumorigenesis.

\section{Materials and methods}

\section{Breeding and Genotypic Analysis Using the Polymerase Chain Reaction (PCR)}

The $\mathrm{mPTEN}+/$ - mice $(129$ Ola $\times$ C57BL/6) with a deletion of exons $3-5$ of $\mathrm{mPTEN}$ were generated. ${ }^{22}$ Male mPTEN + /- mice were mated with 8-weekold wild-type C57BL/6 female mice (Seac Yoshimoto, Fukuoka, Japan) at the Center for Animal Resources and Development, Kumamoto University, Japan. This mating scheme continued until there were eight mice in each group. All animals were maintained in plastic cages in a temperature- and light-controlled room $\left(21-22^{\circ} \mathrm{C}\right.$ and 12-h light/12-h dark) with adequate food and fresh water. The day the vaginal plug was detected was considered day 1 of pregnancy. Pregnant mice were housed individually in plastic cages. At delivery, female pups were separated for the following estrogenic treatments. All experiments were carried out according to the guidelines in the Laboratory Protocol of Animal Handling, Graduate School of Medical Sciences, Kumamoto University. PCR analysis of tail genomic DNA was used to determine the genotypes of mice according to the published protocol, ${ }^{22}$ using the following primers: forward-5'-TGCTATGGGATTT CCTGCAG-3' and reverse- $5^{\prime}$-CAAGCAAAACCAA ATTAAGGGCC-3' for the mutant mPTEN allele, and forward-5'-ACAGACCTAGGCTACTGCTC-3' and reverse-5'-CTAGAGGCAAGACTTCCGTTC-3', specific for the deleted portion of the mPTEN gene.

\section{Neonatal Estrogenic Treatment}

DES (Sigma-Aldrich, St Louis, MO, USA), genistein (Sigma-Aldrich) or estriol $\left(\mathrm{E}_{3}\right)$ (Sigma-Aldrich) was dissolved in ethanol (Sigma-Aldrich) and corn oil 
(Nacalai Tesque, Kyoto, Japan). Female pups were treated daily subcutaneously (s.c.) with the estrogenic agent or vehicle alone from the 1st to 5 th day after birth. The doses were $1 \mathrm{ng} / \mathrm{g} /$ day of DES, $50 \mu \mathrm{g} /$ $\mathrm{g}$ /day of genistein, and $4 \mu \mathrm{g} / \mathrm{g} /$ day of $\mathrm{E}_{3}$. In this experiment, $\mathrm{mPTEN}+/-$ (64 in number) and wildtype mice (64 in number) were divided into four groups of eight animals, which were designated as the DES-treated group, genistein-treated group, $\mathrm{E}_{3}$ treated group and vehicle group. First, eight pups of each group of both $\mathrm{mPTEN}+1-$ and wild-type mice were killed on the 6th day after birth to evaluate the estrogenic activity of DES, genistein, and $E_{3}$. The remaining mice were weaned at 21-22 days of age, housed five per cage, and maintained. Newbolds et $a 1^{28,29}$ reported that the same amount of DES exposure induced endometrial carcinomas at 78 weeks, but not at 52 weeks. Therefore, to evaluate the PTEN-related lesions modified by neonatal estrogenic agents, we killed the mice at 52 weeks of age, before the development of carcinomas directly induced by the neonatal estrogenic treatment.

\section{Measurement of Body and Uterine Wet Weights of mPTEN + $/$ - and Wild-Type Mice}

To evaluate the estrogenic activity of DES, genistein, and $E_{3}$ on the uteri, eight female pups per group of the treated animals were killed by inhalation of diethylether (Wako Pure Chemical Industries, Osaka, Japan) on the morning of day 6 after birth. At 52 weeks of age, the female mice were killed by inhalation of diethylether followed by cervical dislocation to evaluate the influence of neonatal estrogenic exposure on their uteri.

In both age groups, body weights were first recorded. On dissection, the uteri were collected quickly, trimmed of extraneous connective tissue, and uterine wet weights then recorded. The percentage ratios of the uterine wet weight to body weight in the estrogenic treatment groups were compared with that of the vehicle group. Data are expressed as the mean \pm standard error (s.e.).

\section{Histological Examination}

One horn of the uterus removed from each mouse was stored at $-80^{\circ} \mathrm{C}$ for molecular assay. The other horn was fixed in $10 \%$ buffered formalin, embedded in paraffin, and $4-\mu$ m-thick sections cut. Tissue sections were stained with hematoxylin and eosin (H\&E) and examined under a light microscope. H\&Estained sections were reviewed by the same gynecological pathologist. The uterine sections were analyzed and diagnosed as endometrial CAH and adenocarcinoma according to the 'World Health Organization Classification of Tumors' for the female genital tract. ${ }^{40}$

\section{Analysis of Stromal Cell Density}

The number of endometrial stromal cells was quantified in the H\&E-stained sections of all groups using a VM-60 Video Micrometer System (Olympus Co., Tokyo, Japan). The numbers of stromal cells from three random areas $\left(1000 \mu \mathrm{m}^{2}\right)$ of each group were averaged.

\section{Real-Time Quantitative Reverse Transcription-PCR for Hoxa 10 and Hoxa 11 Expression}

Total RNA was extracted using TRIzol reagent (Invitrogen, Carlsbad, CA, USA) from the uterine tissue of one horn from mice of all groups. After RNA extraction, cDNA was generated with $2.5 \mu \mathrm{g}$ of total RNA using Superscript II reverse transcriptase (Invitrogen) according to the manufacturer's instructions.

Quantification of PCR products was conducted using a fluorescence-based real-time detection method (ABI Prism 7700 Sequence Detection TaqMan System; Applied Biosystems, Forster City, CA, USA). Assay-on-Demand primers and probes were used for Hoxa 10 and Hoxa 11, and an internal control gene, glyceraldehyde-3-phosphate dehydrogenase (GAPDH) (Applied Biosystems). The PCR was carried out with $2 \times$ TaqMan Universal PCR master mix (Applied Biosystems), $1.25 \mu \mathrm{l}$ of $20 \times$ Assay-on-Demand (primer and probes), and $2 \mu \mathrm{l}$ of cDNA in a $25 \mu \mathrm{l}$ final reaction mixture. Conditions consisted of $50^{\circ} \mathrm{C}$ for $2 \mathrm{~min}$ and $95^{\circ} \mathrm{C}$ for $10 \mathrm{~min}$, followed by 40 cycles of $15 \mathrm{~s}$ of denaturation at $95^{\circ} \mathrm{C}$ and a combined annealingextension step at $60^{\circ} \mathrm{C}$ for $1 \mathrm{~min}$. A negative control, consisting of nuclease-free water in place of template cDNA, was included in each PCR run. The RNA of vas deferens removed from wild-type male mice, which express Hoxa 10 and Hoxa $11,{ }^{41}$ was used as a control calibrator on each plate.

\section{Statistics}

Arithmetic means and s.e.'s were calculated for each group. The significance of differences between groups was determined using the protected least significant difference of Fisher's test (ANOVA analysis). $\quad P<0.05$ was considered significant. Statistical analysis was performed using the statistical software package StatView 5.0 version (SAS Institute Inc., Cary, NC, USA).

\section{Results}

Ratio of Uterine Wet Weight to Body Weight at 6 Days after Neonatal Treatment with DES, Genistein, or $\mathbf{E}_{3}$

In mPTEN $+/$ - mice, when compared with vehicle alone, the DES and $E_{3}$ treatments resulted in 
$166.47 \pm 14.72 \%$ and $187.54 \pm 31.21 \%$, respectively, gain in the relative ratio of uterine wet weight to body weight (Figure 1, left side; $P<0.01$ ). In wildtype mice, both agents also increased the ratio to $163.43 \pm 12.44 \%$ and $176.88 \pm 9.40 \%$, respectively (Figure 1, right side; $P<0.01$ ). Although the ratio was not statistically significant, genistein treatment also increased the uterine weight ratio to $134.40 \pm 9.41 \%$ and $142.08 \pm 6.51 \%$ in $\mathrm{mPTEN}+/-$ and wild-type mice, respectively (Figure 1).

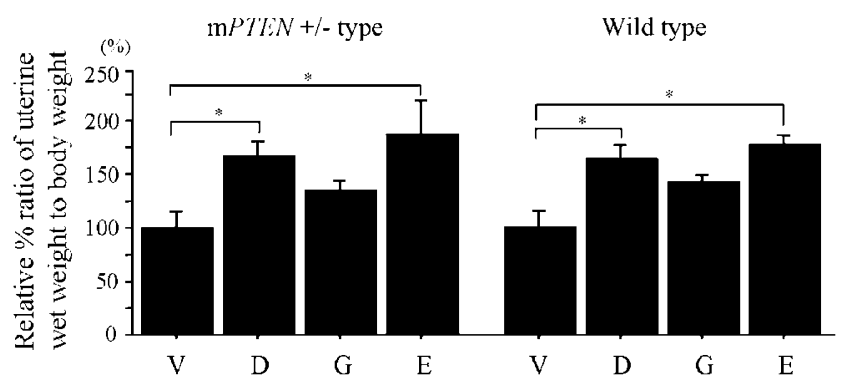

Figure 1 Comparison of hormonal activity of DES, genistein, and $\mathrm{E}_{3}$ in the neonate. Percentage ratio of uterine wet weight to body weight of mice at day 6 after birth. The relative ratios were significantly increased in mPTEN+/- (left side) and wild-type (right side) mice with DES (D) and $\mathrm{E}_{3}$ (E) treatments compared to vehicle (V) alone. Genistein (G) treatment nonsignificantly increased the ratio. ${ }^{*}$ Significantly different $\left({ }^{*} P<0.01\right)$ from $\mathrm{V}$ alone.

\section{Ratio of Uterine Wet Weight to Body Weight at 52 Weeks after Neonatal Treatment of DES, Genistein, or $\mathrm{E}_{3}$ Treatment}

Uterine wet weights and body weights were examined in 31 wild-type mice and $28 \mathrm{mPTEN}+/-$ mice. Two of the eight $\mathrm{mPTEN}+/-$ mice with DES treatment died at 32 and 44 weeks after treatment: one due to lymphoma and the other due to an unknown cause. At 52 weeks of age, myometrial tumors were observed in one wild-type animal with neonatal DES treatment, and in two $\mathrm{mPTEN}+1-$ mice with neonatal genistein and $E_{3}$ treatments. These three mice were excluded from subsequent analysis. Consequently, in $\mathrm{mPTEN}+1-$ mice, when compared with vehicle alone, the neonatal DES and $\mathrm{E}_{3}$ treatments significantly reduced the weight relative ratio to $44.53 \pm 8.11 \%$ (Figure 2, left side; $P<0.01$ ) and $37.71 \pm 8.88 \%$ (Figure 2, left side; $P<0.01$ ), respectively. In wild-type mice, the neonatal $\mathrm{E}_{3}$ treatment also decreased the weight ratio to $56.61 \pm 5.05 \%$ (Figure 2 , right side; $P<0.05$ ). Macroscopically, atrophic uteri were observed in both the $\mathrm{E}_{3}$ treatment and DES treatment mice. The uteri in mPTEN+/- mice with neonatal $\mathrm{E}_{3}$ treatment showed the most atrophy (Figure 2, left side). In contrast, neonatal DES treatment did not induce significant weight loss $(75.19 \pm 10.61 \%)$ in wild-type mice (Figure 2, right side). In addition, neonatal genistein treatment did not induce signi-

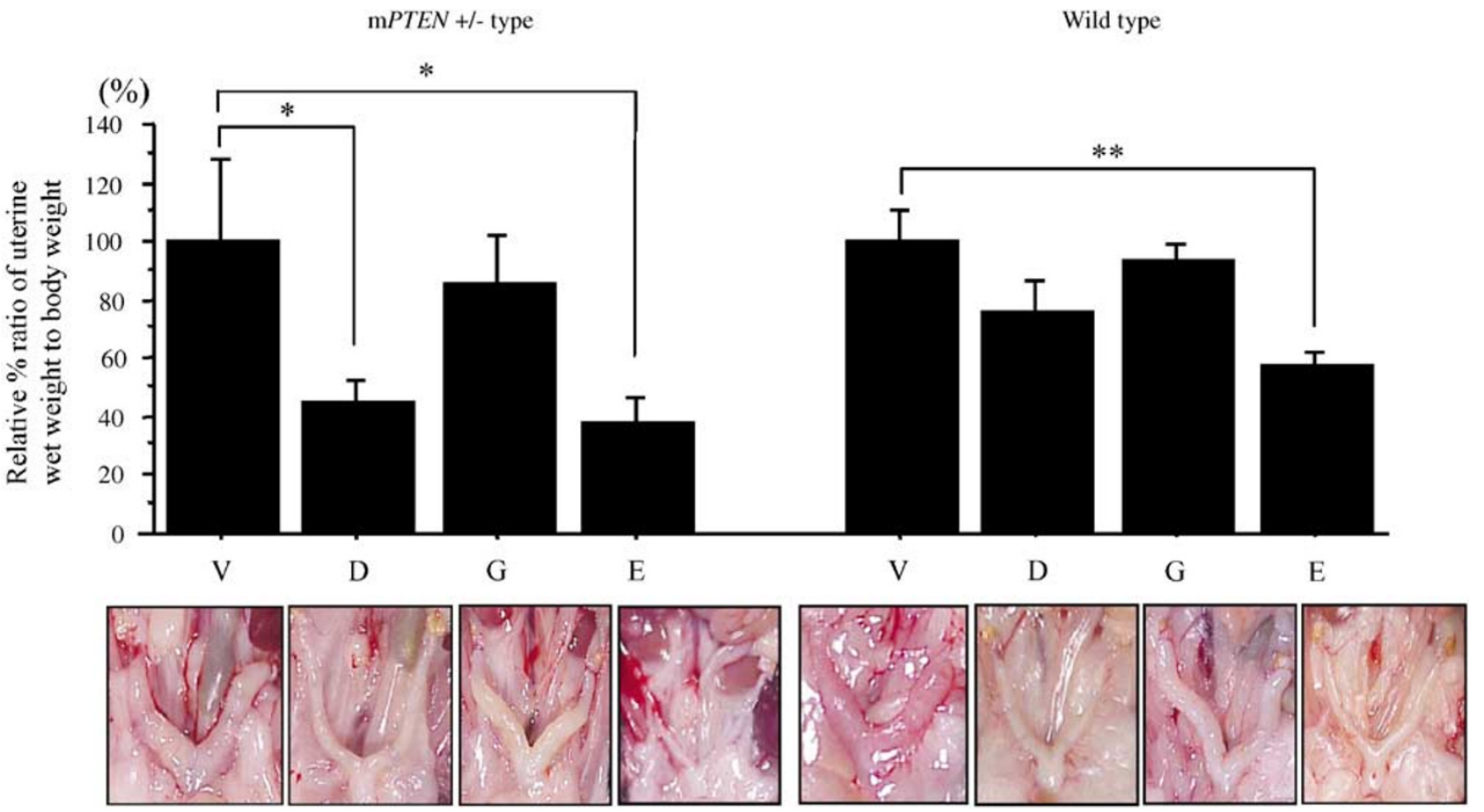

Figure 2 Effects of neonatal treatment with DES, genistein, and $\mathrm{E}_{3}$ on uterine weight in $\mathrm{mPTEN}+/$ - and wild-type mice at 52 weeks of age. Percentage ratio of uterine wet weight to body weight of mice. The relative ratios were significantly decreased in $\mathrm{mPTEN}+/-\mathrm{mice}$ with DES (D) and $E_{3}$ (E) treatments (left side) and in wild-type mice with $E_{3}$ treatment (right side) compared to vehicle (V) alone. Genistein (G) treatment did not induce weight loss. Uteri at killing are shown below the respective graphs. ${ }^{*}$ or ${ }^{*}$ Significantly different $\left({ }^{*} P<0.05,{ }^{*} P<0.01\right)$ from $\mathrm{V}$ alone. 

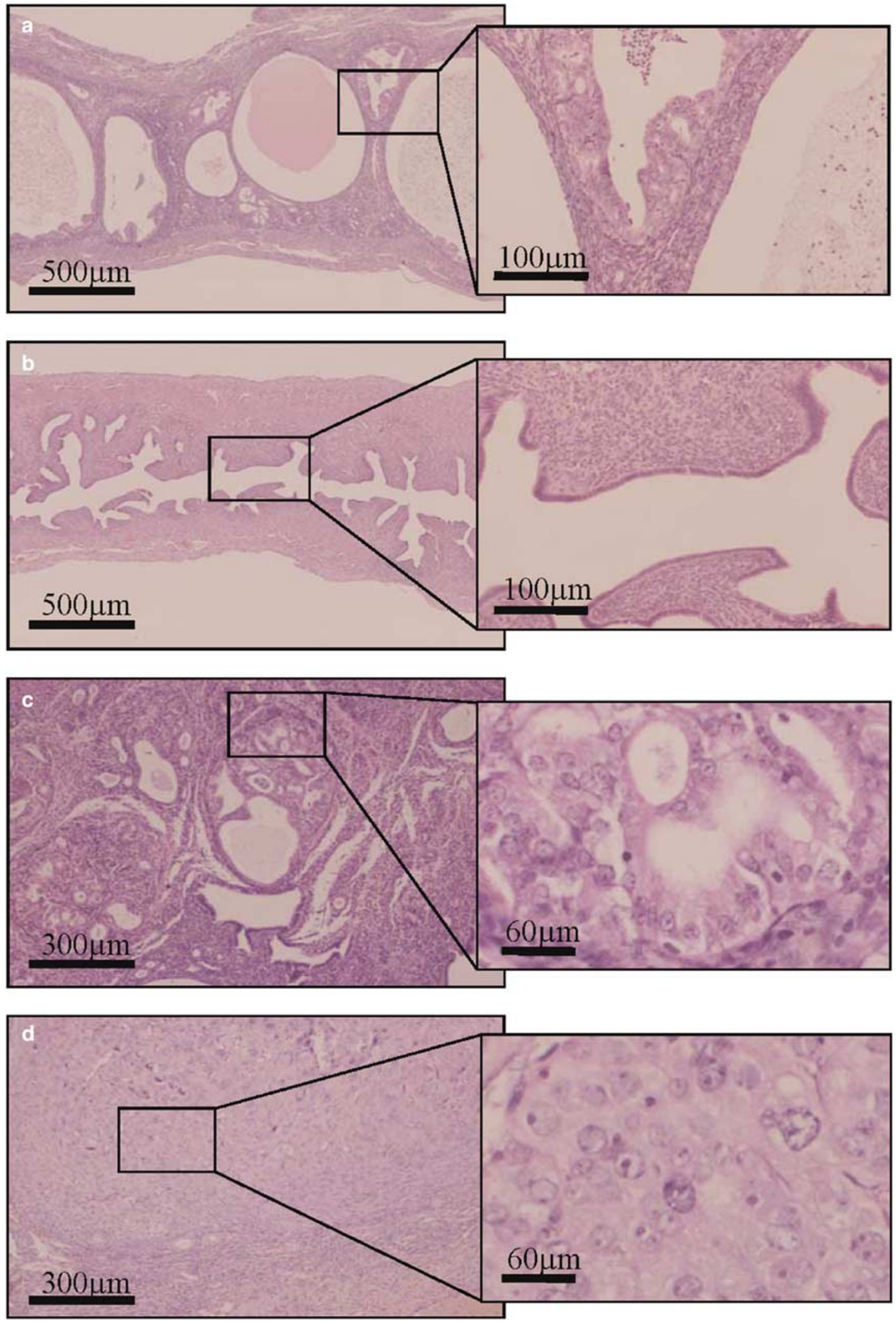

Figure 3 Endometrial lesion profiles in 52-week-old mPTEN+/- and wild-type mice without estrogenic treatment. (a) Multifocal CAH in $\mathrm{mPTEN}+/-$ mice. Magnification $\times 4$, inset, $\times 20$. (b) Normal endometrium in wild-type mice. Magnification $\times 4$, inset, $\times 20$. (c) Well-differentiated adenocarcinoma in two $\mathrm{mPTEN}+/-$ mice. Magnification $\times 10$, inset, $\times 40$. (d) Poorly differentiated adenocarcinoma in a $\mathrm{mPTEN}+/-$ mouse. Magnification $\times 10$, inset, $\times 40$ 
ficant weight loss in either $\mathrm{mPTEN}+/-$ mice $(85.50 \pm 16.36 \%)$ or wild-type mice $(92.63 \pm 5.54 \%)$ (Figure 2).

\section{Endometrial Lesions in mPTEN $+/$ - Mice Without Neonatal Estrogenic Treatments}

In mPTEN $+/-$ mice without neonatal estrogenic treatments, light microscopic evaluation at 52 weeks of age of H\&E-stained sections revealed endometrial lesions characterized by increased architectural complexity and cytological atypia of endometrial glands. The lesions closely resembled in human CAH (Figure 3a). Seven of the eight mPTEN+Imice had multifocal CAH (more than three focal lesions) (Table 1). Notably, age-matched wild-type mice did not develop these lesions (Figure 3b). Two $\mathrm{mPTEN}+$ / - mice had well-differentiated adenocarcinomas characterized by the proliferation of atypical epithelial cells to varying degrees, and cribriform and confluent glands without intervening stroma (Figure 3c). One mPTEN+/- mice had well-differentiated adenocarcinoma coexistent with poorly differentiated adenocarcinoma composed of solid parts in which cells had markedly enlarged, pleomophic nuclei displaying irregular coarse chromatin and prominent, eosinophilic nucleoli (Figure 3d).

\section{Effect of Neonatal Estrogenic Exposure on Endometrial Epithelium}

The incidence of CAH in $\mathrm{mPTEN}+/$ - mice was reduced by neonatal estrogenic treatment; three of the six mice (50\%) with DES treatment, three of the eight mice $(38 \%)$ with genistein treatment, two of the eight mice $(25 \%)$ with $E_{3}$ treatment, and seven of the eight mice $(88 \%)$ with vehicle treatment (Table 1 ; $P<0.05$ in genistein and $\mathrm{E}_{3}$ treatment groups). All of the three DES-treated mice with CAH, one of the three genistein-treated, and one of the two $\mathrm{E}_{3}$-treated mice showed focal lesions, while the others had multifocal lesions (Table 1). The total number of individual focal $\mathrm{CAH}$ was counted in maximum areas of longitudinal sections of one horn in each mouse. The average number of focal CAH per one

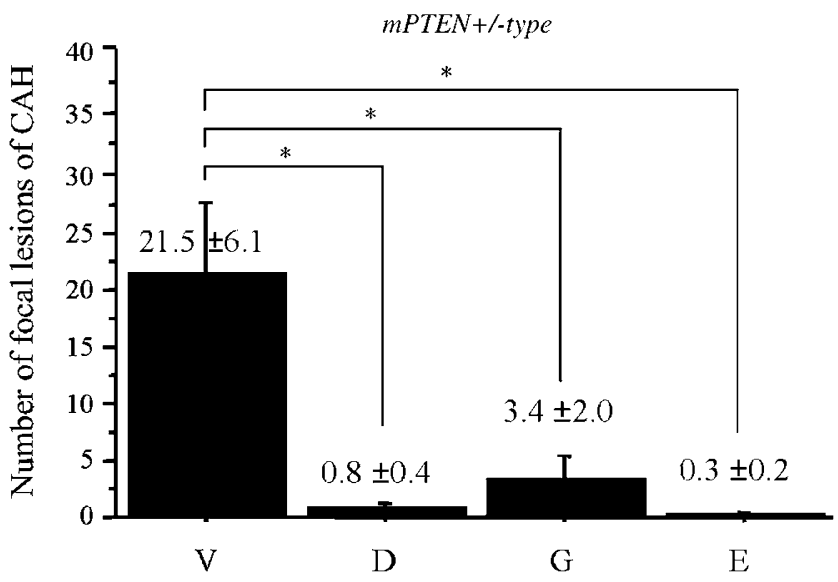

Figure 4 The numbers of focal lesions of CAH in 52-week-old $\mathrm{mPTEN}+/$ - mice after neonatal estrogenic exposure. Focal CAH were counted in H\&E-stained longitudinal sections of one uterine horn per mouse. Each bar shows the mean of focal CAH in each group $(n=8)$, except DES $(n=6,2$ mice died at 32 and 44 weeks after treatment). * Significantly different $(P<0.01)$ from $\mathrm{V}$ alone. Group V: vehicle alone; group D: DES treated; group G: genistein treated; and group E: $\mathrm{E}_{3}$ treated.

Table 1 Histopathological findings in the endometria of 52-week-old mice

\begin{tabular}{|c|c|c|c|c|c|c|c|c|}
\hline \multirow{2}{*}{$\begin{array}{l}\text { Estrogenic agents } \\
\text { Mouse }\end{array}$} & \multicolumn{2}{|c|}{ Vehicle } & \multicolumn{2}{|c|}{$D E S$} & \multicolumn{2}{|c|}{ Genistein } & \multicolumn{2}{|r|}{$E_{3}$} \\
\hline & Wild & mPTEN+/- & Wild & mPTEN+/- & Wild & mPTEN+/- & Wild & mPTEN+/- \\
\hline \multirow[t]{2}{*}{ Epithelium } & & & & & * & & & \\
\hline & & & & NS & & & & \\
\hline \multirow{4}{*}{ Adenocarcinoma } & $0 / 8$ & $3 / 8$ & $\stackrel{*}{*} 0 / 8$ & $0 / 6$ & $0 / 8$ & $1 / 8$ & $0 / 8$ & $0 / 8$ \\
\hline & 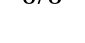 & & & & $*$ & 170 & 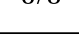 & 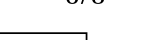 \\
\hline & & & & * & & & & \\
\hline & & $\Gamma$ & NS & & & 1 & & \\
\hline \multirow[t]{3}{*}{ Complex atypical hyperplasia } & $0 / 8$ & $7 / 8$ & $0 / 8$ & $3 / 6$ & $\begin{array}{c}0 / 8 \\
* *\end{array}$ & $3 / 8$ & $0 / 8$ & $2 / 8$ \\
\hline & & $\Gamma$ & & ** & & & & \\
\hline & & 1 & $* *$ & & & & & \\
\hline (Multiple foci & $0 / 8$ & $7 / 8$ & $0 / 8$ & $0 / 6$ & $0 / 8$ & $2 / 8$ & $0 / 8$ & $1 / 8$ \\
\hline Focal & $0 / 8$ & $0 / 8$ & $0 / 8$ & $3 / 6$ & $0 / 8$ & $1 / 8$ & $0 / 8$ & $1 / 8$ \\
\hline Squamous metaplasia & $0 / 8$ & $0 / 8$ & $5 / 8$ & $0 / 6$ & $0 / 8$ & $0 / 8$ & $0 / 8$ & $0 / 8$ \\
\hline \multicolumn{9}{|l|}{ Stroma } \\
\hline Hyalinization & $0 / 8$ & $0 / 8$ & $6 / 8$ & $2 / 6$ & $4 / 8$ & $4 / 8$ & $4 / 8$ & $0 / 8$ \\
\hline Atrophy & $0 / 8$ & $0 / 8$ & $1 / 8$ & $1 / 6$ & $0 / 8$ & $0 / 8$ & $2 / 8$ & $4 / 8$ \\
\hline
\end{tabular}

$\mathrm{NS}=$ nonsignificant, compared with vehicle group.

${ }^{*} P<0.05$, compared with vehicle group.

${ }^{*} P<0.01$, compared with vehicle group. 
uterine horn was significantly lower in $\mathrm{mPTEN}+/$ mice with DES, genistein, and $E_{3}$ treatments than in the mice with vehicle alone (Figure $4 ; P<0.01$ ). Moreover, while three of the eight (38\%) $\mathrm{mPTEN}+\mathrm{I}$ mice with vehicle treatment had adenocarcinomas (Figure 3c and d), none of the mPTEN+I- mice with DES and $E_{3}$ treatments, and one of the eight $(13 \%) \mathrm{mPTEN}+/$ - mice with genistein treatment had adenocarcinomas (Table 1). The incidence of adenocarcinomas in the mPTEN + / - mice with DES and $E_{3}$ treatments was significantly lower than that in the mice with vehicle alone (Table 1; $P<0.05$ ). Neonatal estrogenic treatments induced neither $\mathrm{CAH}$ nor adenocarcinomas in wild-type mice (Figure 5a-c). As for different epithelial lesions, squamous metaplasia developed in five of the eight wild-type mice with neonatal DES treatment (Figure 5a), but not in the other mice (Table 1).

\section{Effect of Neonatal Estrogenic Exposure on the Endometrial Stroma}

Endometrial stroma was characterized by hyalinization or atrophy after neonatal estrogenic treatment. Hyaline was deposited in the endometrial stroma in the mPTEN+ / - mice with DES treatment (two of the six mice) and genistein treatment (four of the eight mice) (Figure $5 \mathrm{~d}$ and e) and in all treated wild-type mice (Figure 5a-c, Table 1). The endometrial stroma was atrophic in DES- and $\mathrm{E}_{3}$-treated wild-type (one of the eight mice with DES treatment and two of the eight mice with $\mathrm{E}_{3}$ treatment) and $\mathrm{mPTEN}+/$ - mice (one of the six mice with DES treatment and four of the eight mice with $E_{3}$ treatment) (Figure $5 f$, Table 1). Neither hyalinization nor atrophy of the stroma was found in any mice with vehicle alone (Table 1). The density of stromal cells was significantly reduced in both $\mathrm{mPTEN}+/$ - and wild-type mice with DES, genistein, and $E_{3}$ treatments compared with vehicle alone (Figure 6a and $\mathrm{b} ;{ }^{*} P<0.05$ and ${ }^{*} P<0.01$ ). In $\mathrm{mPTEN}+/$ - mice treated neonatally with estrogenic agents, CAH were rare in the hyalinized or atrophic area of the stroma, whereas in the same mice CAH developed in the areas containing sufficient stromal cells (Figure 7).

\section{Expression of Hoxa 10 and Hoxa 11 in the Uteri of 52-Week-Old Mice after Neonatal Estrogenic Treatment}

Hoxa genes were highly expressed in the uteri of $\mathrm{mPTEN}+\mathrm{I}-$ mice without estrogenic treatment. Hoxa 10 showed $1.25 \pm 0.70$-fold, and Hoxa 11 $1.75 \pm 1.55$-fold, increased expression over that of
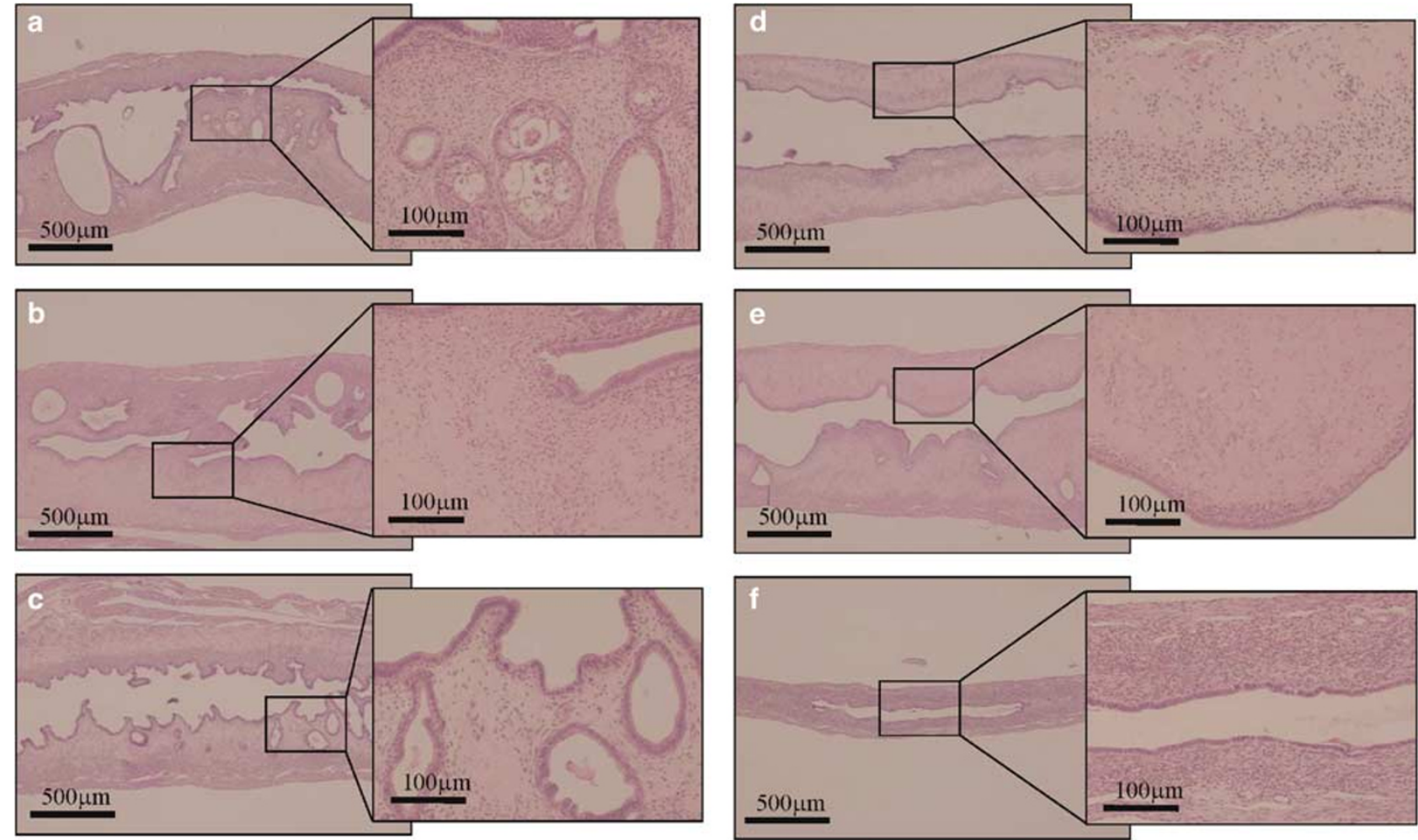

Figure 5 Morphological alterations in endometrium in 52-week-old wild-type and mPTEN+/- mice neonatally treated with DES, genistein, and $\mathrm{E}_{3}$. (a-c) representative wild-type mice with DES, genistein, and $\mathrm{E}_{3}$ treatments, respectively, showing stromal hyalinization. Squamous metaplasias are only present in mice with DES treatment (a). (d-f) representative mPTEN+/- mice with DES, genistein, and $\mathrm{E}_{3}$ treatments, respectively, showing stromal hyalinization and scanty or absence of glands in the stroma. Magnification $\times 4$, inset $\times 20$. 
wild-type mice (Figure 8a and b). Neonatal estrogenic exposure significantly decreased the expression level of Hoxa 10 (0.56 \pm 0.42 -fold; Figure 8a; $P<0.05)$ and Hoxa $11(0.51 \pm 0.44$-fold; Figure 8b; $P<0.05)$ in the uteri of $\mathrm{mPTEN}+/-$ mice with genistein treatment, Ноха $10(0.50 \pm 0.58$-fold; Figure 8a; $P<0.05)$ and Hoxa $11(0.45 \pm 0.20$-fold; Figure 8b; $P<0.01)$ in the mice with $\mathrm{E}_{3}$ treatment, and Hoxa 11 alone in the mice with DES treatment $(0.51 \pm 0.32$ fold; Figure $8 \mathrm{~b} ; P<0.05$ ), when compared with the vehicle mice. No significant differences in the mRNA expression level of these genes were observed among the groups of wild-type mice (Figure 8a and b).

\section{Discussion}

In humans, the use of exogenous estrogen as hormone replacement therapy has been suggested by many studies to significantly increase the risk of adenocarcinoma of the endometrium in postmenopausal women. ${ }^{42}$ Tamoxifen, a therapeutic agent used for breast carcinoma, is a potent synthetic estrogen known to increase the risk of developing endometrial carcinoma. ${ }^{43}$ PCOS with unopposed estrogen action on the endometrium is associated with endometrial carcinoma. ${ }^{44}$ Obesity with unopposed estrogen action is also a well-known risk factor for endometrial carcinomas. ${ }^{45}$ Animal model studies have demonstrated the induction of endometrial carcinomas after neonatal treatment with estrogenic agents, that is, DES, ${ }^{28,29,46}$ genistein, ${ }^{29}$ $17 \beta$-estradiol, ${ }^{47}$ tamoxifen, ${ }^{48} p$-t-octylphenol, ${ }^{49}$ and bisphenol A. ${ }^{50}$ However, the role of genotoxic, epigenetic, and hormonal actions of neonatal estrogenic exposure remains unclear in tumor initiation. Simultaneously, the neonatal estrogenic agents are also well known to induce morphological alterations of the endometrium during development of the reproductive tract in mice. ${ }^{30-32}$
We first hypothesized that low doses of neonatal estrogenic agents stimulate PTEN-related carcinogenesis. Contrary to our expectations, at 52 weeks of

a

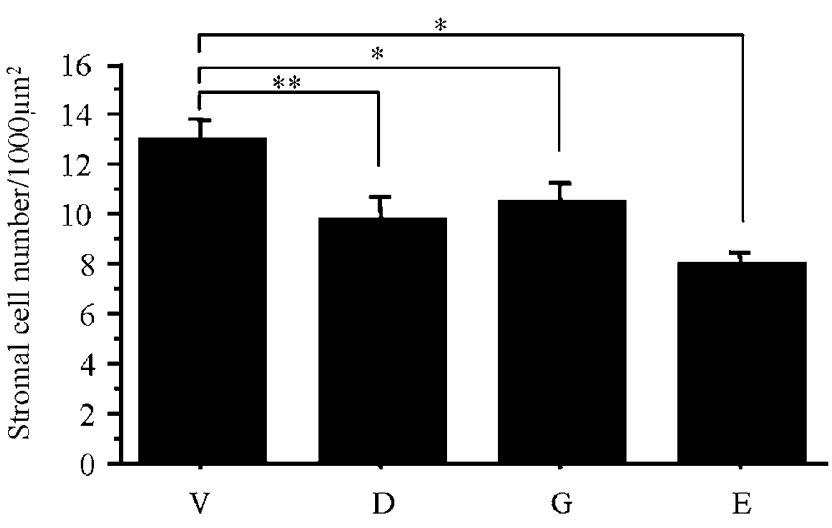

b Wild type

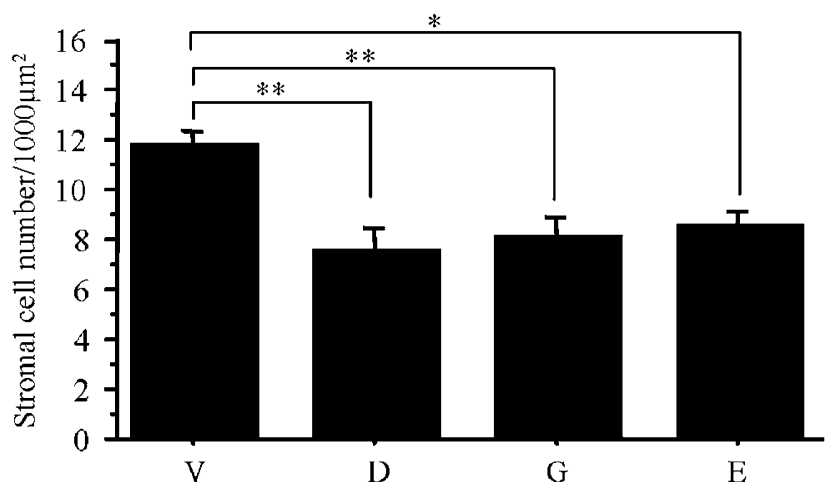

Figure 6 Stromal cell density was calculated by counting the cell number in three fields of vision $\left(1000 \mu \mathrm{m}^{2}\right)$ at a magnification of $\times 40$ /section of vehicle-treated (V), DES-treated (D), genisteintreated (G), and $\mathrm{E}_{3}$-treated (E) groups of $\mathrm{mPTEN}+/$ - (a) and wildtype (b) mice. Each bar shows the mean number of stromal cells in each group $(n=8$, except group $\mathrm{D}$ of $\mathrm{mPTEN}+/-; n=6)$. * or ${ }^{*}$ Significantly different $\left({ }^{*} P<0.05,{ }^{*} P<0.01\right)$ from $\mathrm{V}$ alone.

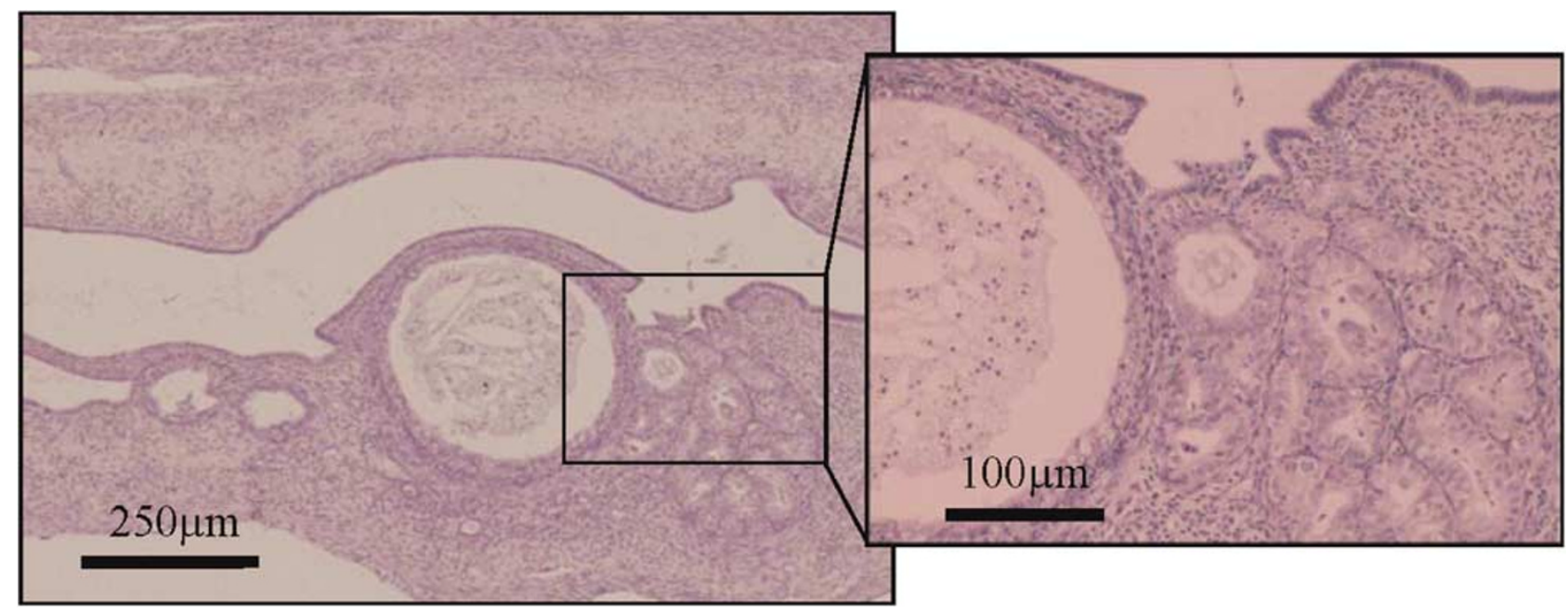

Figure 7 Photomicrographs of an endometrium of 52-week-old mPTEN+/- mice after neonatal exposure to estrogenic agents. H\&Estained tissue sections from a mouse with genistein treatment. CAH of the glands were surrounded by sufficient stromal cells; on the opposite side, there were no CAH in the hyalinized stroma. Magnification $\times 4$, inset $\times 20$. 


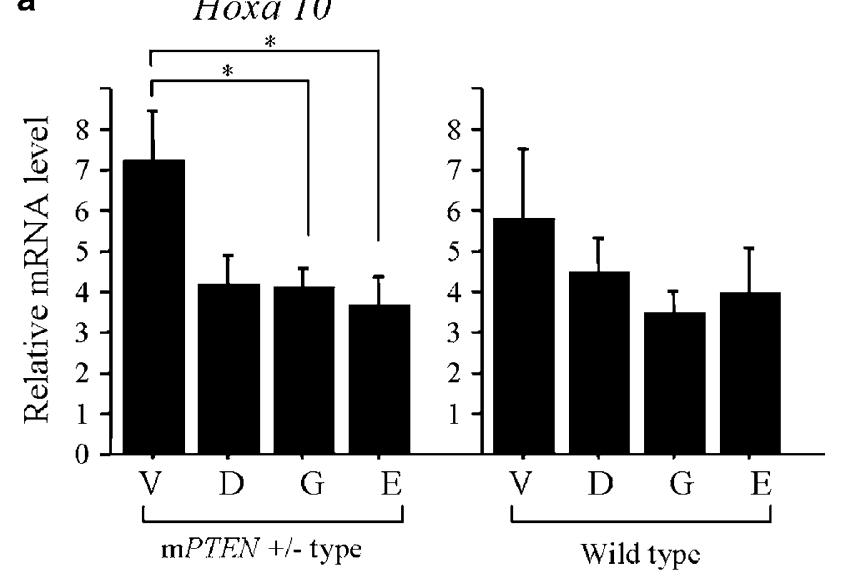

b

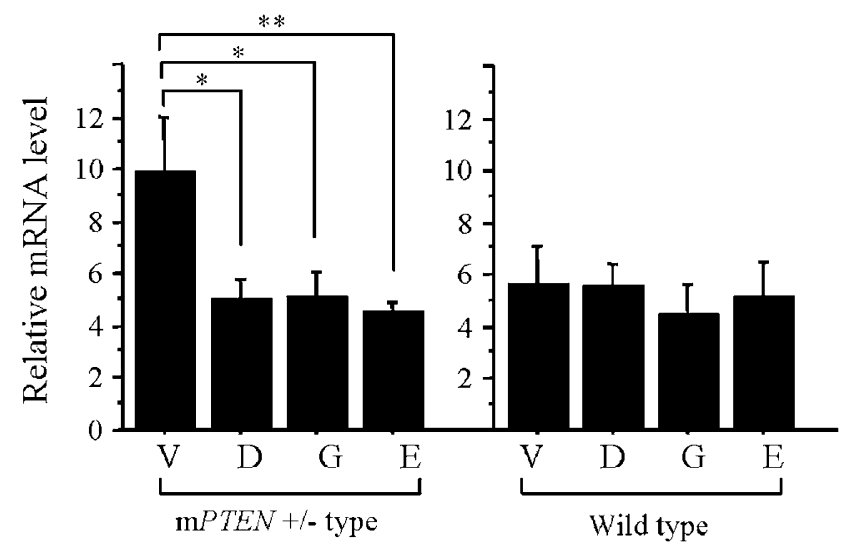

Figure 8 (a and b) Hoxa 10 and Hoxa 11 expression in the uteri of $\mathrm{mPTEN}+/-$ and wild-type mice treated neonatally with DES, genistein, and $E_{3}$, as detected by real-time RT-PCR. The relative mRNA levels of Hoxa 10 (a) and Hoxa 11 (b) are shown in reference to $G A P D H$. Each bar shows the mean of eight mice, except the DES-treated group (D) $(\mathrm{mPTEN}+/-$ mice $=5$, wild $=7)$ and $\mathrm{E}_{3}$-treated group (E) (mPTEN+/ - mice $\left.=7\right)$. In the DES- and $\mathrm{E}_{3}$-treated groups, one mouse in each group had myometrial tumors, and RNA was not available for one mouse in the DEStreated group of mPTEN $+/$ - mice. * or ${ }^{*}$ Significantly different $\left({ }^{*} P<0.05,{ }^{*} P<0.01\right)$ from $\mathrm{V}$ alone. Group G: genistein-treated group.

age, the incidence of $\mathrm{CAH}$ and adenocarcinomas of the endometrium had dramatically decreased upon neonatal estrogenic treatment in $\mathrm{mPTEN}+/$ - mice. Coincidentally, atrophic and/or hyalinized stroma was often observed in the mice after neonatal estrogenic treatment, and CAH and adenocarcinomas rarely occurred in the epithelium adjacent to the affected stroma. Recent molecular studies have focused on the clustered homeobox genes Hoxa 10 and Hoxa 11. Both are expressed in the developing female reproductive tract, particularly endometrium. ${ }^{39,51}$ The developmental expression pattern of these genes is similar in mice and human. ${ }^{39}$ Exposure to DES during development has been shown to irreversibly repress the expression of Hoxa 10 and Hoxa 11, and is responsible for the altera- tions in the developmental program of uterine differentiation. ${ }^{33,34,37}$ The importance of both genes has been explained by studies using null mice. Hoxa 10 and Hoxa 11 knockout mice resulted in a significant loss of endometrial stromal cells. ${ }^{35,52}$ Moreover, the neonatal DES-induced repression of Hoxa 10 and Hoxa 11 expression in the uterus reduces the number of stromal cells in mice. ${ }^{53}$ In the present study, exposure to neonatal estrogenic agents, other than DES, reduced Hoxa 10 and Hoxa 11 expression in mPTEN+/- mice. The repression of these genes may be responsible for the reduction in stromal cells and the rare development of $\mathrm{CAH}$ and adenocarcinomas. Recently, human endometrial and ovarian endometrioid adenocarcinomas have been shown to frequently over express Hoxa $10{ }^{54,55}$ Hoxa 10 expression may play another different role in carcinogenesis with endometrioid features.

In the present study, the neonatal estrogenic agents did not enhance endometrial tumorigenesis in mice. Kabbarah et $a l^{56}$ treated mice carrying knockout alleles for MLH1 or MSH2 with DES during the neonatal period, and also failed to develop endometrial carcinomas. Hence, the mechanism of endometrial tumorigenesis induced by neonatal estrogenic exposure most likely differs from that of endometrial carcinogenesis associated with mutations of PTEN or DNA mismatch repair genes. Distinct alterations in gene expression following neonatal DES exposure have been reported for $E G F, E G F$ receptor, c-fos, c-jun, c-myc, bax, and bcl-2. ${ }^{57-59}$ Although further studies will be required, neonatal estrogenic exposure might affect such genes, and induce carcinomas independently of surrounding stromal cells in adult mice.

Approximately 3 million women in the United States were treated with DES during pregnancy in an attempt to prevent threatened and repeated abortions in late 1940 to early $1970 s .{ }^{60}$ In 1971 , Herbst et $a l^{61}$ pointed a strong association between DES use in pregnancy and the occurrence of vaginal clear-cell adenocarcinoma in exposed female offspring. The developmental anomalies of the female reproductive tract including T-shaped hypoplastic uteri and malformation of the cervix were also observed in the DES-exposed offspring. ${ }^{61,62}$ Although 705 cases of clear-cell adenocarcinomas of the vagina and cervix have been reported, there were only two pathologically confirmed case reports of endometrial carcinomas. ${ }^{63,64}$ In a recent cohort study, the incidence of endometrial carcinomas in DESexposed persons was lower than that of unexposed persons. ${ }^{65}$ These findings in human might be consistent with this study using the mice model.

Taken together, neonatal estrogenic treatments exerted an inhibitory, rather than stimulatory, effect on PTEN-related carcinogenesis via stromal alterations. CAH and carcinomas rarely occurred in the atrophic and/or hyalinized stroma, resulting from an irreversible repression of Hoxa 10 and Hoxa 11 through these neonatal estrogenic exposures. This 
study can be expected to provide new insight into the interaction between the endometrial epithelium and stroma in endometrial carcinogenesis in vivo.

\section{Acknowledgements}

This work was supported by a Grant-in-Aid for Scientific Research (15591764) from the Japan Society for the Promotion of Science (H Tashiro). We thank Professor Tak W Mak, Department of Medical Biophysics, Advanced Medical Discovery Institute, University of Toronto, Canada, for providing the mPTEN heterozygous mice.

\section{References}

1 Pisani P, Bray F, Parkin DM. Estimates of the worldwide prevalence of cancer for 25 sites in the adult population. Int J Cancer 2002;97:72-81.

2 Bokhman JV. Two pathogenetic types of endometrial carcinoma. Gynecol Oncol 1983;15:10-17.

3 Sherman ME, Sturgeon S, Brinton LA, et al. Risk factors and hormone levels in patients with serous and endometrioid uterine carcinomas. Mod Pathol 1997; 10:963-968.

4 Katabuchi H, Rees BV, Lambers AR, et al. Mutations in DNA mismatch repair genes are not responsible for microsatellite instability in most sporadic endometrial carcinoma. Cancer Res 1995;55:5556-5560.

5 Ellenson LH. hMLH1 promoter hypermethylation in microsatellite instability-positive endometrial carcinoma. Am J Pathol 1999;155:1399-1401.

6 Enomoto T, Inoue M, Perantoni AO, et al. K-ras activation in premalignant and malignant epithelial lesions of the human uterus. Cancer Res 1991;51: 5308-5314.

7 Ignar-Trowbridge D, Risinger JI, Dent GA, et al. Mutations of the Ki-ras oncogene in endometrial carcinoma. Am J Obstet Gynecol 1992;167:227-232.

8 Saegusa M, Hashimura M, Yoshida T, et al. catenin mutations and aberrant nuclear expression during endometrial tumorigenesis. Br J Cancer 2001;84: 209-217.

9 Tashiro H, Blazes MS, Wu R, et al. Mutations in PTEN are frequent in endometrial carcinoma but rare in other common gynecological malignancies. Cancer Res 1997; 57:3935-3940.

10 Risinger JI, Hayes AT, Berchuck A, et al. PTEN/ MMAC1 mutations in endometrial cancers. Cancer Res 1997;57:4736-4738.

11 Risinger JI, Hayes K, Maxwell GL, et al. PTEN mutation in endometrial cancers is associated with favorable clinical and pathologic characteristics. Clin Cancer Res 1998;4:3005-3010.

12 Kohler MF, Berchuck A, Davidoff AM, et al. Overexpression and mutation of p53 in endometrial carcinoma. Cancer Res 1992;52:1622-1627.

13 Kohler MF, Carney P, Dodge R, et al. p53 overexpression in advanced-stage endometrial adenocarcinoma. Am J Obstet Gynecol 1996;175:1246-1252.

14 Lax SF, Kendall B, Tashiro H, et al. The frequency of p53, K-ras mutations, and microsatellite instability differs in uterine endometrial and serous carcinoma. Cancer 2000;88:814-824.

15 Li J, Yen C, Liaw D, et al. PTEN, a putative protein tyrosine phosphatase gene mutated in human brain, breast, and prostate cancer. Science 1997;275: 1943-1947.

16 Steck PA, Pershouse MA, Jasser SA, et al. Identification of a candidate tumor suppressor gene, MMAC1, at chromosome 10q23.3 that is mutated in multiple advanced cancers. Nat Genet 1997;15:356-362.

17 Cantley LC, Neel BG. New insight into tumor suppression: PTEN suppresses tumor formation by restraining the phosphoinositide 3-kinase/AKT pathway. Proc Natl Acad Sci USA 1999;96:4240-4245.

18 Mutter GL, Lin M, Fitzgeralds JT, et al. Altered PTEN expression as a diagnostic marker for the earliest endometrial precancers. J Natl Cancer Inst 2000;92:924-931.

19 Latta E, Chapman WB. PTEN mutations and evolving concepts in endometrial neoplasia. Curr Opin Obstet Gynecol 2002;14:59-65.

20 Levine RL, Cargile CB, Blazes MS, et al. PTEN mutations and microsatellite instability in complex atypical hyperplasia, a precursor lesion to uterine endometrial carcinoma. Cancer Res 1998;58:32543258.

21 Konopka B, Paszko Z, Janiec-Jankowska A, et al. Assessment of the quality and frequency of mutations occurrence in PTEN gene in endometrial carcinomas and hyperplasias. Cancer Lett 2002;178:43-51.

22 Suzuki A, Pompa JL, Stambolic V, et al. High cancer susceptibility and embryonic lethality associated with mutation of the PTEN tumor suppressor gene in mice. Curr Biol 1998;8:1169-1178.

23 Hansen GM, Justice MJ. Pten, a candidate tumor suppressor gene, maps to mouse chromosome 19. Mamm Genome 1997;9:88-90.

24 Podsypanina K, Ellenson LH, Nemes A, et al. Mutation of Pten/Mmac1 in mice causes neoplasia in multiple organ system. Proc Natl Acad Sci USA 1999;96:15631568.

25 Stambolic V, Tsao M-S, Macpherson D, et al. High incidence of breast and endometrial neoplasia resembling human Cowden syndrome in PTEN+/- mice. Cancer Res 2000;60:3605-3611.

26 Vollmer G. Endometrial cancer: experimental models useful for studies on molecular aspects of endometrial cancer and carcinogenesis. Endocr Relat Cancer 2003; 10:23-42.

27 Wang H, Douglas W, Lia M, et al. DNA mismatch repair deficiency accelerates endometrial tumorigenesis in PTEN heterozygous mice. Am J Pathol 2002;160: 1481-1486.

28 Newbold RR, Bullock BC, McLachlan JA. Uterine adenocarcinoma in mice following developmental treatment with estrogen: a model for hormonal carcinogenesis. Cancer Res 1990;50:7677-7681.

29 Newbold RR, Banks EP, Bullock BC, et al. Uterine adenocarcinoma in mice treated neonatally with genistein. Cancer Res 2001;61:4325-4328.

30 McLachlan JA, Newbold RR, Bullock BC. Long-term effects on the female mouse genital tract associated with prenatal exposure to diethylstilbestrol. Cancer Res 1980;40:3988-3999.

31 Bern HA, Edery M, Mills KT, et al. Long-term alterations in histology and steroid receptor levels of the genital tract and mammary gland following 
neonatal exposure of female BALB/cCrgl mice to various doses of diethylstilbestrol. Cancer Res 1987;47: 4165-4172.

32 Iguchi T. Cellular effects of early exposure to sex hormones and antihormones. Int Rev Cytol 1992;139: $1-57$.

33 Ma L, Benson GV, Lim H, et al. Abdominal B (Abd B) Hoxa genes: regulation in adult uterus by estrogen and progesterone and repression in Müllerian duct by the synthetic estrogen diethylstilbestrol (DES). Dev Biol 1998;197:141-154.

34 Block K, Kardana A, Igarashi $\mathrm{P}$, et al. In utero diethylstilbestrol (DES) exposure alters hox gene expression in the developing Müllerian system. FASEB J 2000;14:1101-1108.

35 Benson GB, Lim H, Paria BC, et al. Mechanism of reduced fertility in Hoxa 10 mutant mice: uterine homeosis and loss of maternal Hoxa 10 expression. Development 1996;122:2687-2696.

36 Gendron RL, Paradis H, Hsieh-Li HM, et al. Abnormal uterine and glandular function associated with maternal reproductive defects in Hoxa 11 null mice. Biol Reprod 1997;56:1097-1105.

37 Li S, Ma L, Chiang T, et al. Promoter CpG methylation of Hoxa 10 and Hoxa 11 in mouse uterus not altered upon neonatal diethylstilbestrol exposure. Mol Carcinogen 2001;32:213-219.

38 Hsieh-Li HM, Witte DP, Weinstein M, et al. Hoxa 11 structure, extensive antisense transcription, and function in male and female fertility. Development 1995; 121:1373-1385.

39 Taylor HS, Vander Heuvel GB, Igarashi P. A conserved Hox axis in the mouse and human female reproductive system: late establishment and persistent adult expression of the Hoxa cluster genes. Biol Reprod 1997;57: 1338-1345.

40 Tavassoli FA, Devilee P. Pathology and Genetics of Tumors of the Breast and Female Genital Organs, World Health Organization Classification of Tumors, 2003. IARC Press: Lyon, pp 217-232.

41 Bomgardner D, Hinton BT, Turner TT. $5^{\prime}$ Hox genes and Meis 1, a Hox-DNA binding cofactor, are expressed in adult mouse epididymis. Biol Reprod 2003;68: 644-650.

42 Grady D, Gebretsadik T, Petitti D. Hormone replacement therapy and endometrial cancer risk: a metaanalysis. Obstet Gynecol 1995;85:304-313.

43 Bergman L, Beelen MLR, Gallee MPW, et al, the Comprehensive Cancer Centres' ALTERT Group. Risk and prognosis of endometrial cancer after tamoxifen for breast cancer. Lancet 2000;356:881-887.

44 Dahlgren E, Friberg LG, Johansson S, et al. Endometrial carcinoma; ovarian dysfunction-a risk factor in young women. Eur J Obstet Gynecol Reprod Biol 1991;41: 143-150.

45 Kaaks R, Lukanova A, Kurzer MS. Obesity, endogenous hormones, and endometrial cancer risk: a synthetic review. Cancer Epidemiol Biomarkers Prev 2002;11: 1531-1543.

46 Marselos M, Tomatis L. Diethylstilbestrol: II, pharmacology, toxicology and carcinogenicity in experimental animals. Eur J Cancer 1993;29:149-155.

47 Liehr JG. Is estradiol a genotoxic mutagenic carcinogen? Endocr Rev 2000;21:40-54.

48 Newbold RR, Jefferson WN, Padilla-Burgos E, et al. Uterine carcinoma in mice treated neonatally with tamoxifen. Carcinogenesis 1997;18:2293-2298.
49 Yoshida M, Katsuda S, Tanimoto T, et al. Induction of different types of uterine adenocarcinomas in donryu rats due to neonatal exposure to high-dose $p$ - $t$ octylphenol for different periods. Carcinogenesis 2002; 23:1745-1750.

50 Suzuki A, Sugihara A, Uchida K, et al. Developmental effects of perinatal exposure to bisphenol A and diethylstilbestrol on reproductive organs in female mice. Reprod Toxicol 2002;16:107-116.

51 Kitajewski J, Sassoon D. The emergence of molecular gynecology: homeobox and wnt genes in the female reproductive tract. Bioessays 2000;22:902-910.

52 Wong KHH, Wintch HD, Capecchi MR. Hoxa 11 regulates stromal cell death and proliferation during neonatal uterine development. Mol Endocrinol 2004; 18:184-193.

53 Couse JF, Dixon D, Yates M, et al. Estrogen receptor- $\alpha$ knockout mice exhibit resistance to the developmental effects of neonatal diethylstilbestrol exposure on the female genital tract. Dev Biol 2001;238:224-238.

54 Lane DB, Rutherford TJ, Taylor HS. Hoxa 10 expression in endometrial adenocarcinoma. Tumor Biol 2004;25: 264-269.

55 Cheng W, Liu J, Yoshida H, et al. Lineage infidelity of epithelial ovarian cancers is controlled by Hox genes that specify regional identity in the reproductive tract. Nat Med 2005;11:531-537.

56 Kabbarah O, Sotelo AK, Mallon MA, et al. Diethylstilbestrol effects and lymphogenesis in Mlh1-deficient mice. Int J Cancer 2005;115:666-669.

57 Nelson KG, Sakai Y, Eitzman B, et al. Exposure to diethylstilbestrol during a critical developmental period of the mouse reproductive tract leads to persistent induction of two estrogen-regulated genes. Cell Growth Differ 1994;5:595-606.

58 Falck L, Forsberg J-G. Immunohistochemical studies on the expression and estrogen dependency of EGF and its receptor and c-fos proto-oncogene in the uterus and vagina of normal and neonatally estrogen-treated mice. Anat Rec 1996;245:459-471.

59 Zheng X, Hendry III WJ. Neonatal diethylstilbestrol treatment alters the estrogen-regulated expression of both cell proliferation and apoptosis-related protooncogenes (c-jun, c-fos, c-myc, bax, bcl-2, and bcl-x) in the hamster uterus. Cell Growth Differ 1997;8:425-434.

60 Herbst AL. Behavior of estrogen-associated female genital tract cancer and its neoplasia following intrauterine exposure to diethylstilbestrol (DES). Gynecol Oncol 2000;76:147-156.

61 Herbst AL, Ulfelder H, Poskanzer DC. Adenocarcinoma of the vagina: association of maternal stilbestrol therapy with tumor appearance in young women. N Engl J Med 1971;28:878-881.

62 Kurman RJ. Abnormalities of the genital tract following stillbestrol exposure in utero. Recent Results Cancer Res 1979;66:161-174.

63 Barter JF, Austin JM, Shingleton HM. Endometrial adenocarcinoma after in utero diethylstilbestrol exposure. Obstet Gynecol 1986;67:84S-85S.

64 Keller C, Nanda R, Shannon RL, et al. Concurrent primaries of vaginal clear cell adenocarcinoma and endometrial adenocarcinoma in a 39-year old woman with in utero diethylstilbestrol exposure. Int J Gynecol Cancer 2001;11:247-250.

65 Hatch EE, Palmer JR, Titus-Ernstoff L, et al. Cancer risk in women exposed to diethylstilbestrol in utero. JAMA 1998;280:630-634. 